\title{
EDUCACION CONTINUADA
}

\section{Haga usted el diagnóstico}

\author{
Primera parte \\ Gerzaín Rodríguez ${ }^{1}$, Nelly Ordóñez ${ }^{2}$ \\ ' Laboratorio de Patología, Instituto Nacional de Salud; profesor titular de Patología, Facultad de Medicina, \\ Universidad Nacional de Colombia, Bogotá, D.C., Colombia. \\ ${ }^{2}$ Laboratorio de Patología, Instituto Nacional de Salud, Bogotá, D.C., Colombia.
}

Un hombre de 43 años de edad, natural y procedente de Bogotá, consultó por presentar una placa eritematosa y descamativa de $2 \times 2 \mathrm{~cm}$ situada en el dorso nasal, que apareció hace 4 meses después de trauma leve. La placa involucionó espontáneamente en su gran mayoría y la lesión residual, cicatrizal, se extirpó. Su imagen histopatológica se ilustra en las figuras 1 a 3. El paciente tiene como antecedentes una rinoplastia hace 15 años y resección de cuerpo extraño (silicona) del dorso nasal, hace 9 años. Es fumador de marihuana y aspira cocaína ocasionalmente.

La biopsia muestra focos de hiperplasia pseudoepiteliomatosa y varios granulomas en la dermis

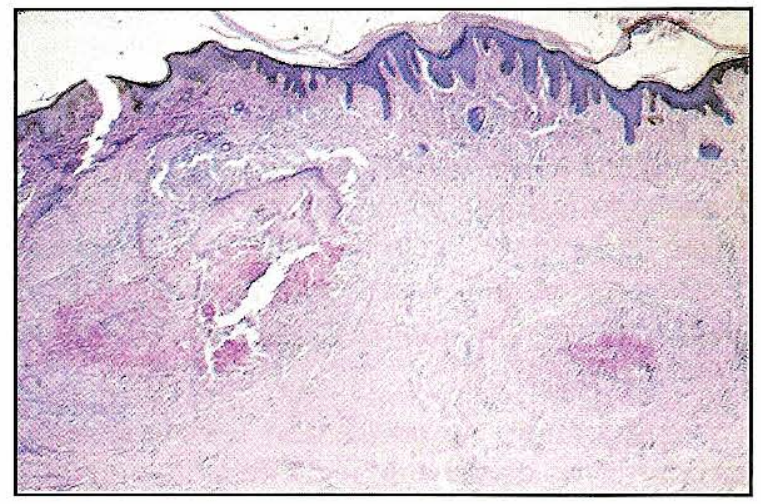

Figura 1. HE, 2,5X.

\section{Correspondencia:}

Gerzaín Rodríguez, Laboratorio de Patología, Instituto Nacional de Salud, Apartado aéreo 80334, Bogotá, D.C., Colombia, S.A.

grodriguez@hemagogus.ins.gov.co

Recibido: 06/12/00; aceptado: 02/03/01 media y profunda, muy bien definidos, rodeados por fibrosis concéntrica y constituidos por un centro con necrosis fibrinoide, detritus nucleares y cantidad variable de neutrófilos, rodeado por abundantes macrófagos vacuolados, células epitelioides y células gigantes de tipo cuerpo extraño (figuras 1-3), que conforman granulomas mixtos.

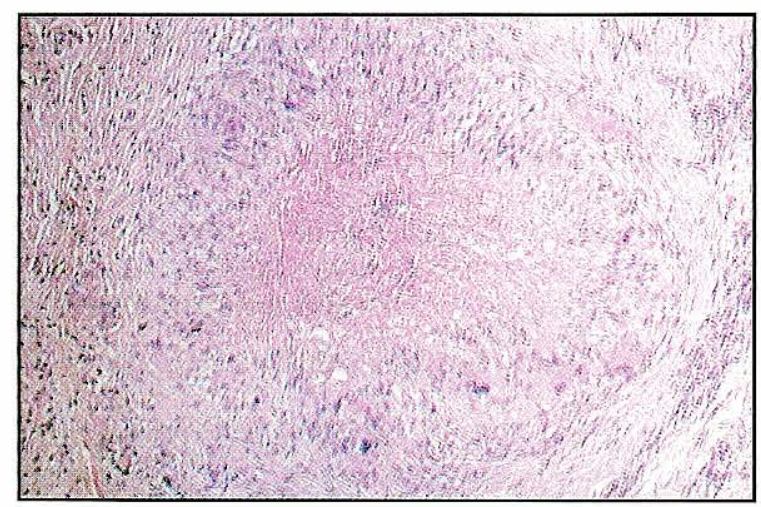

Figura 2. HE, 12X.

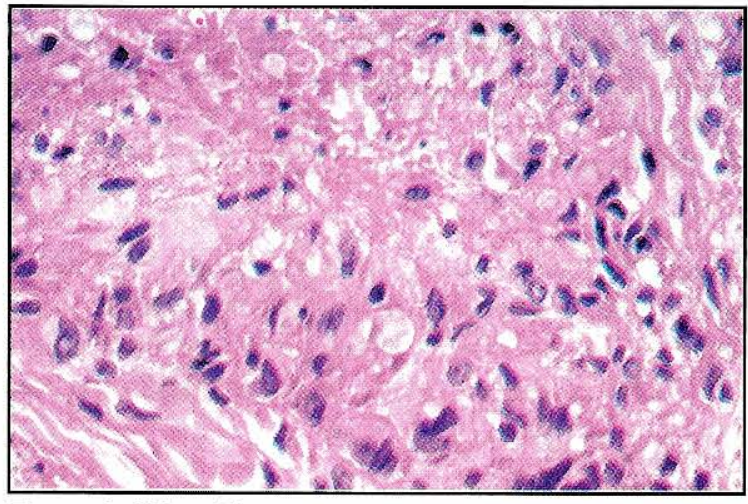

Figura 3. HE, 64X. 